\section{Cureus}

Received 12/21/2015

Review began 01/22/2016

Review ended 02/02/2016

Published 03/05/2016

\section{(c) Copyright 2016}

Avila et al. This is an open access article distributed under the terms of the Creative Commons Attribution License CC-BY 3.0., which permits unrestricted use, distribution, and reproduction in any medium, provided the original author and source are credited.

\title{
Outcomes and Complications of Minimally Invasive Surgery of the Lumbar Spine in the Elderly
}

\author{
Mauricio J. Avila ${ }^{1}$, Christina M. Walter ${ }^{2}$, Ali A. Baaj ${ }^{3}$ \\ 1. Neurological Surgery, NewYork-Presbyterian/Weill Cornell Medical College 2. Neurological Surgery, \\ The University of Arizona 3. Neurological Surgery, New York-Presbyterian/Weill Cornell Medical College
}

$\square$ Corresponding author: Mauricio J. Avila, avila.mao@gmail.com

Disclosures can be found in Additional Information at the end of the article

\section{Abstract}

Introduction: Minimally invasive spine (MIS) surgery is gaining popularity in the elderly. With aging population and a strong desire for all patients to remain physically active, this trend will likely continue. Previous studies have reported clinical outcomes in the elderly undergoing MIS surgery; however, most of these studies encompass multiple surgeons at different sites and thus present heterogeneous experiences. In this work, we investigate the clinical outcomes and complications of all lumbar MIS procedures performed in patients over 65 years of age by a single surgeon.

Methods: A retrospective analysis of a prospectively maintained database of spine surgeries was performed. Twenty-six patients who underwent 27 procedures were included.

Results: Mean age at surgery was 72 years (range 64-86). The mean BMI was $30.2 \mathrm{~kg} / \mathrm{m}^{2}$, patients had an average of 5 comorbidities, took 9 medications, and $15 \%$ were smokers. The mean symptoms duration was 40.6 months with the numeric rating scale (NRS) and the Oswestry disability index (ODI) prior to surgery of 7.68 and 50\% respectively. Six different types of procedures were performed, the most common was the interlaminar decompression and fusion (ILIF) followed by MIS laminectomy, microdiscectomy and MIS lateral fusion (XLIF). 74\% of the surgeries were done at a single level. Average blood loss was $43 \mathrm{~mL}$, and the mean length of stay was 1.7 days. There were three complications (11.1\%): one urinary tract infection, one pulmonary embolism, and one new, postoperative weakness. At six months follow-up, there was a mean improvement of $27 \%$ in ODI, and a 5.6 improvement in NRS (both p<0.05); 90\% of patients stated they would have the surgery again.

Conclusion: Minimally invasive lumbar spine surgery is both safe and highly effective in the elderly population. Patient selection is of utmost importance. This data will add to the existing literature on the overall safety and effectiveness of these procedures in the elderly population.

Categories: Neurosurgery, Orthopedics

Keywords: minimally invasive surgery, aged, patient outcome assessment, spine, adult

\section{Introduction}

The fastest growing segment of the population in the United States are individuals over 65 years of age [1-2], with projections of a further increment of $16.5 \%$ by 2020 [1]. The increasing number of older adults worldwide represents a challenge to any healthcare system [3]. 
Epidemiological data shows that back pain is the most common musculoskeletal condition affecting any population [4-5] with a prevalence of $4-33 \%$ at any given time [4].This number is even higher in older adults with an estimated prevalence of 56\% [6]. The high prevalence and the disability of a chronic condition such as back pain can limit the normal functioning of an older adult compared to those without back pain [7-8]. As older adults are living longer free of disabilities [3], it is important to find a way to safely treat older patients with low back pain.

Geriatric patients represent a surgical challenge due to their comorbidities and normal physiological changes with aging [2, 9]. Minimally invasive spine (MIS) surgery is aimed at avoiding complications related to the open procedures with less disruption of the normal anatomy, less blood loss and shorter hospitalizations [10-13]. Previous research has shown the feasibility of MIS surgery in older patients [14-15]; however, the data was retrieved from different surgeons in one or multiple centers.

The aim of this study was to evaluate outcomes and complications of patients over 65 treated with MIS surgery of the lumbar spine by a single surgeon in a single institution.

This work was approved by the Human Subjects Protection Program-University of Arizona.

\section{Materials And Methods}

A retrospective chart review from a prospectively maintained database was performed until December 2014 for patients over 65 years of age who underwent minimally invasive lumbar spine surgery by a single surgeon in a single center. Our inclusion criteria were: patients who were 65 years or older at the time of surgery, patients who had any lumbar degenerative spine pathology, patients who had a minimally invasive procedure, and patients who had appropriate clinical and radiographic follow-up.

Patients' demographics (age, weight, comorbidities, medications etc.), length of stay, estimated blood loss, immediate complications, surgical morbidity, mortality, and type of procedure were retrieved. The patients' reported outcomes such as numerical rating scale (NRS) for pain, and Oswestry disability index (ODI) were retrieved before surgery and at every follow-up (starting at week six) after surgery. We used paired sample t-test to compare means between groups and set a statistical significance of $\mathrm{p}<0.05$. We also used measures of central tendency for continuous variables. Data was retrieved and processed with Microsoft Excel. Statistical analysis was performed with SPSS software (IBM) version 20.

\section{Results}

There was a slight predominance of female patients in this series (54\%). The mean age at surgery was 72 years old with a range of 65 to 86 years. Overall, the mean BMI was $30.2 \mathrm{~kg} / \mathrm{m}^{2}$ (Obesity). The mean duration of patients' symptoms before surgery was 40 months, and 10\% of the patients had a previous spine surgery. The mean estimated blood loss (EBL) during surgery was $43.9 \mathrm{~mL}$, and the mean length of stay was 1.6 days. The most common affected level was L4-L5. The complete patients' demographics are presented in Table 1. 


\section{Cureus}

\section{Characteristic}

Age (range)

Sex

Male (\%)

Female (\%)

BMI (range)

Comorbidities (range)

Medications(ranges)

Smoker (\%)

Symptoms duration in months (range)

Number of previous non-surgical treatment (range)

Previous spine surgery (\%)

Estimated blood loss (range)

Length of stay (range)

Follow up (range)

Affected level

L1-L2 (\%)

L2-L3 (\%)

L3-L4 (\%)

L4-L5 (\%)

L5-S1 (\%)

Multiple levels (\%)
Value

$72(65-86)$

$12(46)$

$14(54)$

30.2 (17.4-39)

$5(2-10)$

$9(3-24)$

$4(15.4)$

40.6 months $(0.5-180)$

$2.5(1-4)$

$10(38.5)$

$43.85 \mathrm{~mL}(10-300)$

1.65 days $(1-5)$

7.8 months (2-24)

$1(3.7)$

$2(7.4)$

$3(11.1)$

$11(40.7)$

$3(11.1)$

7 (26)

TABLE 1: Baseline patients' characteristics

Six different types of procedures were performed (Figure 1); the most common was the interlaminar decompression and fusion (ILIF) followed by MIS laminectomy, microdiscectomy, and MIS lateral fusion (XLIF). 


\section{Cureus}

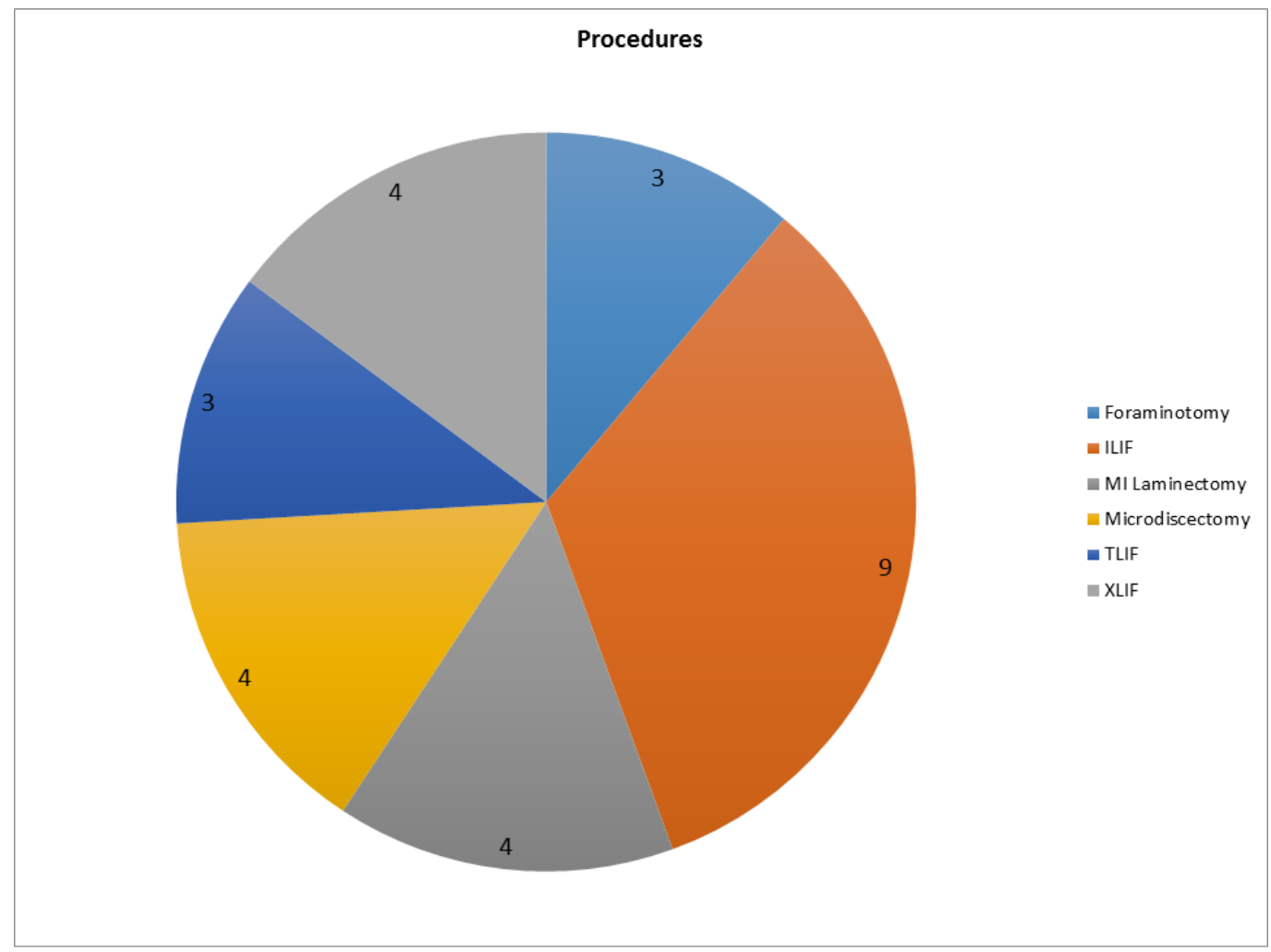

FIGURE 1: Type of MIS procedures performed

ILIF: Interlaminar Lumbar Interbody Fusion

TLIF: Transforaminal Interbody Fusion

XLIF: Extreme Lateral Interbody Fusion

MI: Minimally Invasive

Regarding patients reported outcomes (Table 2), the greater difference for NRS score was seen at three months with a mean difference of 7 points compared to baseline. Moreover, the difference in NRS was statistically significant at all the different follow-ups (six weeks, three months, six months, and at one year) after surgery.

For the ODI, the greater difference (37\%) was also seen at three months. The results for ODI were also statistically significant at all the follow-up dates after the procedure. After six months there was an overall improvement of $27 \%$ for ODI compared to baseline ODI ( $p=0.018$ ). $90 \%$ of the patients answered that they will have the surgery again. 


\section{Cureus}

\begin{tabular}{|ll|lll|}
\hline Comparison & & Mean Difference of the Pair & $95 \%$ Confidence Interval & p Value \\
\cline { 2 - 4 } NRS PreOp & NRS 6 weeks & 4.95 & $2.67-7.23$ & 0.001 \\
& NRS 3 months & 7.0 & $0.72-5.44$ & $<0.001$ \\
& NRS 6 months & 5.63 & $4.22-7.04$ & $<0.001$ \\
& NRS 1 year & 4.94 & $2.91-6.97$ & 0.001 \\
\hline \multirow{2}{*}{ ODI PreOp* } & ODI 6 weeks & 0.28 & $0.05-0.51$ & 0.029 \\
& ODI 3 months & 0.37 & $0.24-0.51$ & 0.003 \\
& ODI 6 months & 0.27 & $0.007-0.47$ & 0.018 \\
\hline
\end{tabular}

TABLE 2: Results of the patients' reported outcomes

One patient had an NRS and ODI score at two years of follow-up of two and 18\% respectively.

There were three complications in this study (11.1\%). One patient had a urinary tract infection, one patient had a pulmonary embolism diagnosed after surgery that did not carry any clinical consequences for the patient, and finally one patient had right hip flexors and knee extensor weaknesses noticeable at one month after surgery; however, at six months, the patient improved to near normal strength after physical therapy and rehabilitation.

There was no mortality in this cohort.

\section{Discussion}

With the global population aging and life expectancy surpassing 80 years, it is expected that spine surgeons will encounter more elderly patients in their practice [1].

This study shows the feasibility of minimally invasive spine procedure in patients older than 65 years of age performed by a single surgeon in one center. Although aimed at over 65 years, our sample had a mean age of 72 years with one patient who safely underwent surgery at 86 years.

There is a growing body of evidence showing the clinical benefits of treating patients over 65 years old with surgery [14-16]. For this study, we did not include patients who had traumatic fractures; however, it is important to recognize that fractures in the elderly population have increased in frequency over the last few years [17]. The indications for surgery in these patients may be different than for those suffering from degenerative changes [17-18] as well as the profile of complications [17].

Our results show a statistically significant difference (improvement) of the NRS and ODI score starting at two weeks after the surgery. More importantly, is that the results for the ODI score were all above a $10 \%$ difference, which is required to be considered a "clinically significant" difference $[10,19]$. Particularly, ODI improved $28 \%$ at six weeks after surgery, $37 \%$ at three months after surgery, and $27 \%$ at six months after surgery. 
Our complications were transient and all resolved at the patients' last follow-up without any residual injuries. The latter is in accordance of what has been reported in the literature [14-15]. Despite that $38 \%$ of the patients had a previous spine surgery, this fact did not alter our complications rate as only one patient (urinary tract infection) of the three patients with complications had a previous spine surgery; in fact this complication was not directly related to the lumbar spine pathology or the previous surgery.

When approaching a surgery for an elderly patient, it is crucial to have a team of health professionals who allows the patient to be in the best physiological state as possible before surgery $[2,9]$. Figure 1 shows the different type of procedures done in this case series. Several MIS are represented and, aside for 9 ILIF, there was not any clear dominance of one procedure over the others which show how versatile MIS can be for elderly patients. Minimally invasive approaches allow treating lumbar spine pathologies with less disruption of the anatomy and less blood loss compared with open procedures. In cases of patient with multiple comorbidities, it is more desirable to perform MIS surgery due to their mentioned benefits. Furthermore, if the spine surgeon is comfortable with several MIS procedures, the range of elderly patients who could benefit from surgery would increase.

Patient selection before surgery is a key step to succeed when approaching elderly patients. It is of utmost importance to determine the patient's pre-surgical, usual functioning status and have clear goals for the surgery with the patient and family. The evaluation of comorbidities and family support are necessary to ensure a successful procedure. In our cohort, patients had a mean of five comorbidities and were taking nine medications at the time of surgery, which could explain some of the complications [20]. However, as not all the patients with comorbidities had complications, this also shows that having comorbidities does not necessarily preclude surgery in the elderly population.

This study has some limitations. First, it is a retrospective study; nonetheless, we collected the data in a prospective fashion as part of an ongoing database for spinal procedures. Second, some patients did not complete the full scoring system of the ODI, which could have shown more pronounced differences; however, we believe that despite this, the trend is clear toward a clinical and statistically significant difference. Finally, the relatively small sample of this study may limit the generalizability of our results. Nonetheless, as shown previously by other studies [14-15], there are clear benefits in doing surgery in elderly patients.

\section{Conclusions}

Minimally invasive spine surgery in patients over 65 years of age with lumbar degenerative spine pathologies is safe and yields excellent outcomes. Newer surgical techniques allow spine surgeons to offer solutions to high-risk patients with lumbar spine pathologies who wouldn't otherwise tolerate traditional open-spine procedures.

\section{Additional Information}

\section{Disclosures}

Human subjects: Consent was obtained by all participants in this study. Human Subjects Protection Program-University of Arizona issued approval 1410531284A001. Animal subjects: All authors have confirmed that this study did not involve animal subjects or tissue. Conflicts of interest: In compliance with the ICMJE uniform disclosure form, all authors declare the following: Payment/services info: All authors have declared that no financial support was received from any organization for the submitted work. Financial relationships: Ali A. Baaj declare(s) royalties from Thieme Publishers. Handbook of Spine Surgery. Other relationships: All authors have declared that there are no other relationships or activities that could appear to 
have influenced the submitted work.

\section{References}

1. Etzioni DA, Liu JH, Maggard MA, Ko CY: The aging population and its impact on the surgery workforce. Ann Surg. 2003, 238:170-177. 10.1097/01.SLA.0000081085.98792.3d

2. Schlitzkus LL, Melin AA, Johanning JM, Schenarts PJ: Perioperative management of elderly patients. Surg Clin North Am. 2015, 95:391-415. 10.1016/j.suc.2014.12.001

3. Christensen K, Doblhammer G, Rau R, Vaupel JW: Ageing populations: the challenges ahead. Lancet. 2009, 374:1196-1208. 10.1016/s0140-6736(09)61460-4

4. Woolf AD, Pfleger B: Burden of major musculoskeletal conditions. Bull World Health Organ. 2003, 81:646-656.

5. Hartvigsen J, Christensen K, Frederiksen H: Back pain remains a common symptom in old age. A population-based study of 4486 Danish twins aged 70-102. Eur Spine J. 2003, 12:528-534. 10.1007/s00586-003-0542-y

6. Stewart Williams J, Ng N, Peltzer K, et al: Risk factors and disability associated with low back pain in older adults in low- and middle-income countries. Results from the WHO study on global AGEing and adult health (SAGE). PloS One. 2015, 10:e0127880. 10.1371/journal.pone.0127880

7. Rudy TE, Weiner DK, Lieber SJ, Slaboda J, Boston JR: The impact of chronic low back pain on older adults: A comparative study of patients and controls. Pain. 2007, 131:293-301. 10.1016/j.pain.2007.01.012

8. Houde F, Cabana F, Léonard G: Does Age Affect the Relationship Between Pain and Disability? A Descriptive Study in Individuals Suffering From Chronic Low Back Pain. J Geriatr Phys Ther. 2015, May 13:10.1519/jpt.0000000000000055

9. Loran DB, Hyde BR, Zwischenberger JB: Perioperative management of special populations: the geriatric patient. Surg Clin North Am. 2005, 85:1259-1266. 10.1016/j.suc.2005.09.004

10. Alimi M, Hofstetter CP, Pyo SY, Paulo D, Härtl R: Minimally invasive laminectomy for lumbar spinal stenosis in patients with and without preoperative spondylolisthesis: clinical outcome and reoperation rates. J Neurosurg Spine. 2015, 22:339-352. 10.3171/2014.11.spine13597

11. Bina RW, Zoccali C, Skoch J, Baaj AA: Surgical anatomy of the minimally invasive lateral lumbar approach. J Clin Neurosci. 2015, 22:456-459. 10.1016/j.jocn.2014.08.011

12. Alkadhim M, Zoccali C, Abbasifard S, et al: The surgical vascular anatomy of the minimally invasive lateral lumbar interbody approach: a cadaveric and radiographic analysis. Eur Spine J. 2015, 24:906-911. 10.1007/s00586-015-4267-5

13. Al-Khouja LT, Baron EM, Johnson JP, Kim TT, Drazin D: Cost-effectiveness analysis in minimally invasive spine surgery. Neurosurg Focus. 2014, 36:E4. 10.3171/2014.4.focus1449

14. Karikari IO, Grossi PM, Nimjee SM, et al: Minimally invasive lumbar interbody fusion in patients older than 70 years of age: analysis of peri- and postoperative complications. Neurosurgery. 2011, 68:897-902. 10.1227/NEU.0b013e3182098bfa

15. Rosen DS, O'Toole JE, Eichholz KM, et al: Minimally invasive lumbar spinal decompression in the elderly: outcomes of 50 patients aged 75 years and older. Neurosurgery. 2007, 60:503-509. 10.1227/01.neu.0000255332.87909.58

16. Glassman SD, Bridwell K, Dimar JR, Horton W, Berven S, Schwab F: The impact of positive sagittal balance in adult spinal deformity. Spine. 2005, 30:2024-2029.

10.1097/01.brs.0000179086.30449.96

17. Winkler EA, Yue JK, Birk H, et al: Perioperative morbidity and mortality after lumbar trauma in the elderly. Neurosurg Focus. 2015, 39:E2. 10.3171/2015.7.focus15270

18. Abbasi Fard S, Skoch J, Avila MJ, et al: Instability in thoracolumbar trauma: Is a new definition warranted?. J Spinal Disord Tech. 2015, Aug 19:

19. Hägg O, Fritzell P, Nordwall A, Swedish Lumbar Spine Study Group: The clinical importance of changes in outcome scores after treatment for chronic low back pain. Eur Spine J. 2003, 12:12-20.

20. Polanczyk CA, Marcantonio E, Goldman L, et al: Impact of age on perioperative complications and length of stay in patients undergoing noncardiac surgery. Ann Intern Med. 2001, 134:637643. 10.7326/0003-4819-134-8-200104170-00008 